\title{
Physical and Mechanical Properties of Cassava-Bamboo Composite Lumber
}

\author{
Ros Syazmini Mohd Ghani ${ }^{1}$, Razak Wahab ${ }^{1}$, Noor Maisarah Che Musthafa ${ }^{2}$, \\ Nasihah Mokhtar ${ }^{l}$, Mohamad Saiful Sulaiman ${ }^{1}$, Man Djun Lee ${ }^{l}$ \\ ${ }^{1}$ University College of Technology Sarawak, 96000 Sibu, Sarawak. \\ ${ }^{2}$ Universiti Malaysia Sabah, 88400 Kota Kinabalu, Sabah.
}

\begin{abstract}
The study was carried out to determine the physical and mechanical properties of composite lumber made from cassava (Mahinot esculenta Crantz) and bamboo (Bambusa vulgaris) in different ratios which is $100 \%$ cassava with $0 \%$ bamboo, $75 \%$ cassava with $25 \%$ bamboo, $50 \%$ cassava with $50 \%$ bamboo, $25 \%$ cassava with $75 \%$ bamboo and $0 \%$ cassava with $100 \%$ bamboo. The tests samples for determining the strength properties were divided into two categories namely mechanical testing and physical testing. Basic density of the samples was carried out for physical testing. The lowest basic density was in samples with $100 \%$ cassava which is $0.49 \mathrm{~g} / \mathrm{cm}^{3}$ and highest in samples with $100 \%$ bamboo which is $0.68 \mathrm{~g} / \mathrm{cm}^{3}$. Two tests for the mechanical testing are bending test and compression test. In bending test, modulus of elasticity (MOE) and modulus of rupture (MOR) were both highest for samples with $100 \%$ bamboo which the reading of MOE was $16794.03 \mathrm{~N} / \mathrm{mm}^{2}$ and $122.52 \mathrm{~N} / \mathrm{mm}^{2}$ for MOR. Similar to the bending test, compression test is the highest for the samples with $100 \%$ bamboo which are $65.58 \mathrm{~N} / \mathrm{mm}^{2}$. From statistical analysis, the basic density, static bending can compression strength give significant value at $95 \%$ confidence interval.
\end{abstract}

Keywords: composite lumber, cassava-bamboo, basic density, bending test, compression test

\section{INTRODUCTION}

Cassava (Manihot esculenta Crantz) has now become the fourth major energy source in the tropics after rice, sugar and maize [1]. In 2004, the total production of cassava were more than 200 million tons worldwide [2]. In African, Asian and Latin American, the amount of cassava produced exceeds 82 million tons per year. The largest cassava producing countries are Nigeria, Brazil, Thailand, Democratic Republic of Congo and Indonesia [3]. Cassava has been grown in Malaysia for quite some time. Malaysia has been a supplier and exporter of cassava products since the 1970s.

Bambusa vulgaris belongs to the Bambusae family which is the widely grown bamboo around the tropics. This species is easy to grow due to its adaptability to agroclimatic conditions, easily response to vegetative propagation, vigorous growth and quick recovery of clumps after felling. Besides, this bamboo species has high culm strength, can be utilized in various ways and high pulping quality [4].
In recent times, the timber industry is facing problem for the production of timber products due to the shortage of raw materials. Timber species such as meranti (Shorea sp.), kapur (Dryobalanops sp.) and other tropical hardwood are declining in supply due to environmental awareness. According to Malaysia Timber Industry Board, export for major timber products in Malaysia is more than RM 11 billion on 2017. This industry was even listed as Top 10 export product from Malaysia.

Therefore, to protect this industry from slumped, alternative materials and resources are needed to replace timber in wood-based products. For future use, the timber industry can manipulate non-wood lignocellulose sources species such as palm, coconut, kenaf, bamboo and cassava as raw material for the wood processing industry [5].

This study aims to use cassava and bamboo to produce a composite product known as cassavabamboo composite lumber (CBCL). Also, this study is also conducted to study the physical and mechanical properties of the composite product whether it is suitable to be introduced as a new composite product.

Corresponding Author: Ros Syazmini Mohd Ghani, University College of Technology Sarawak, Jalan Universiti, 96000 Sibu, Sarawak, 60199949633 


\section{EXPERIMENT}

\section{Sample Preparation}

The cassava stems obtained from the Tuaran, Sabah. 50 stems of cassava plant were used in this study. While for bamboo, the samples of Bambusa vulgaris were collected from Hutan Simpan Kawang. The number of bamboo samples taken was ten (10) stems.

Before the sample preparation process, bamboo and cassava stem was heated using palm oil for the pre-treatment process to increase the life-span of the cassava stem and bamboo [6]. However, the temperature should reach $80^{\circ} \mathrm{C}$ before bamboo, and cassava stem was put into the oil. After that, the samples were left until the oil temperature reaches $160^{\circ} \mathrm{C}$. When this temperature is reached, the samples are left to be heated for 60 minutes in that temperature.

In the process of preparing samples, tubers of cassava and bamboo are cut to the predetermined size. The length of cassava stalks is cut equally regarding length, width and thickness (Figure 1). For bamboo samples, it was cut into the parts of the predetermined section as in Figure 2.

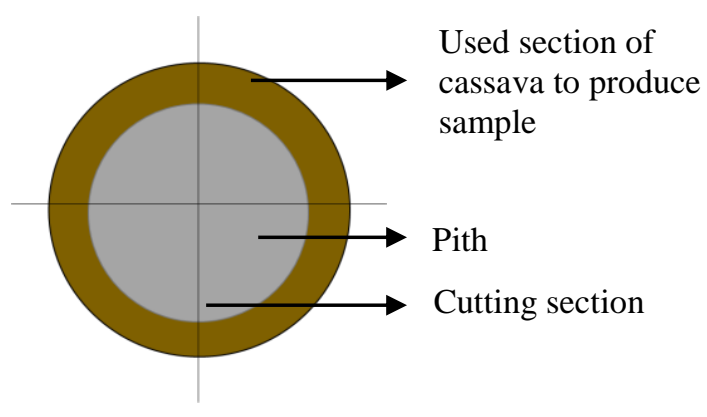

Fig 1 Cutting dimension of cassava stem

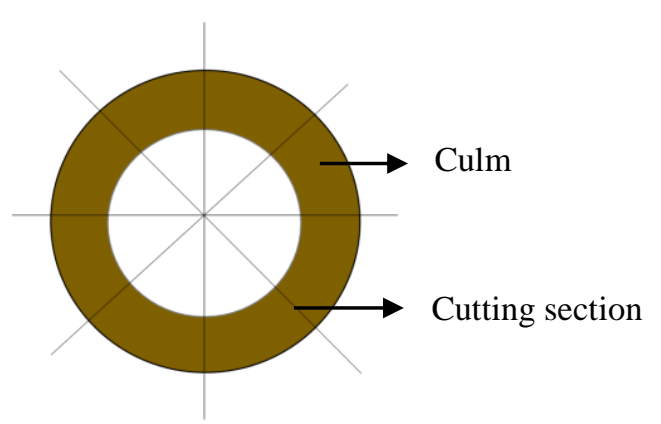

Fig 2 Cutting dimension of bamboo

The moisture content of the cassava tubers and the bamboo sticks standardized at $12 \%$. The composite board were prepared according to different ratios which were $100 \%$ cassava, $70 \%$ cassava with $30 \%$ bamboo, $50 \%$ cassava with $50 \%$ bamboo, $30 \%$ cassava with $70 \%$ bamboo and $100 \%$ bamboo. The samples are glued together using polyvinyl acetate (PVAc) resin. Before being glued together, samples should be kept clean and dry without any dirt or foreign matter. The samples were left until the adhesive becomes dried and turns from liquid to solid. It eventually produces cassava-bamboo composite boards (CBCL).

\section{Physical Testing}

Physical tests conducted for CBCL samples were basic density tests. The sample size was $2 \times 2 \times 2 \mathrm{~cm}$ each. The initial weight is taken before being put into the oven at $102^{\circ} \mathrm{C}$ overnight. After 24 hours, the weight was recorded again, and the basic density of the samples can be calculated using the following formula:

Basic density $(\mathrm{g} / \mathrm{cm} 3)=($ oven dry mass $) /$ (green volume)

\section{Mechanical Testing}

Mechanical testing was carried out according to ISO standard that was done using Mechanical Testing Machine (MTM). Modulus of Elasticity (MOE) and Modulus of Rupture (MOR) were tested for static bending test. The sample size for MOE and MOR were $20 \times 20 \times 320 \mathrm{~mm}$. The value of MOE and MOR were generated from the MTM machine. Besides that, using the same machine, the compression test parallel to the grain are also conducted.

\section{Statistical Analysis}

Data obtained from tests on physical and mechanical properties of CBCL are collected and analyzed. The results were analyzed using correlation analysis to find the relationship between the characteristics of CBCL.

\section{RESULT AND DISCUSSION}

Figure 3 shows the average of the basic density tests carried out on cassava-bamboo composite lumber that have different strip ratios. The basic density of CBCL is $0.49 \mathrm{~g} / \mathrm{cm}^{3}$ for $100 \%$ cassava, $0.51 \mathrm{~g} / \mathrm{cm}^{3}$ for $75 \%$ cassava and $25 \%$ bamboo, $0.55 \mathrm{~g} / \mathrm{cm}^{3}$ for $50 \%$ cassava and $50 \%$ bamboo, $0.62 \mathrm{~g} / \mathrm{cm}^{3}$ for $25 \%$ cassava and $75 \%$ bamboo and $0.68 \mathrm{~g} / \mathrm{cm}^{3}$ for only bamboo composite board.

Overall, the results of the basic density test carried out show the different ratio of cassava and bamboo in the CBCL increasing the basic density value of the sample studied when the bamboo strips increase. This is because from the result we can see the basic 
density of $100 \%$ cassava is lower than basic density of $100 \%$ bamboo. The basic density of Bambusa vulgaris in this study is comparable with the study done by Anokye et al., [7] which he concludes that density of Bambusa vulgaris are comparable with density of Gigantachloa scortechinii which is one of the widely used bamboo in Malaysia.

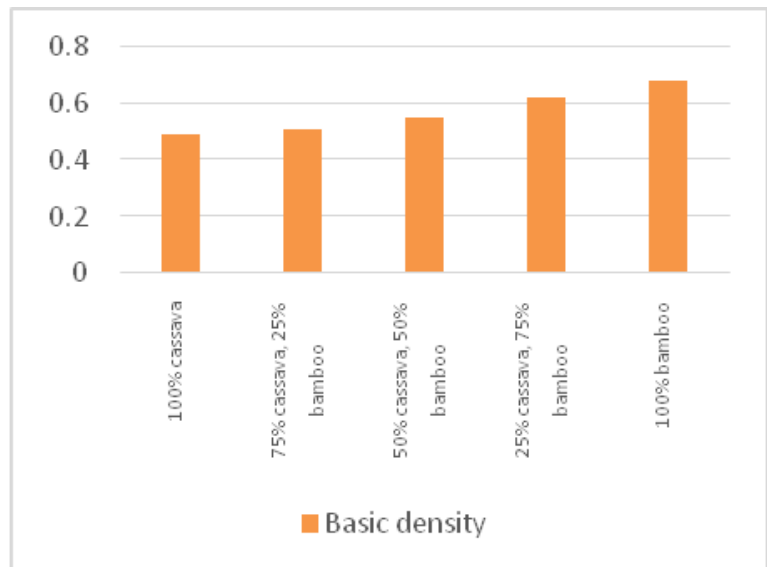

Fig 3 The basic density of cassava-bamboo composite lumber

In mechanical testing, there are two types of tests that have been carried out using a Mechanical Testing Machine (MTM). This mechanical test is conducted using the ISO 22157 standard. Mechanical test results obtained from static bending tests and parallel compression tests.

Through the results of the mechanical test obtained, the change regarding the strength of the CBCL is known. The result determined whether the different ratio of tuber and bamboo content in composite board gives different strengths.

Figure 4 shows the modulus of elasticity (MOE) and modulus of rupture (MOR) of static bending. The MOE of cassava-bamboo composite lumber increase with increasing composition of bamboo. At $100 \%$ cassava, the MOE was only 1834.22 $\mathrm{N} / \mathrm{mm}^{2}$, but with $100 \%$ bamboo, the MOE increases up to $16794.03 \mathrm{~N} / \mathrm{mm}^{2}$. The sample with $100 \%$ bamboo has almost $90 \%$ MOE higher than the cassava board. This is due to the density of the bamboo which were much higher than cassava stems. Besides, the MOE of $100 \%$ bamboo CBCL is comparable with airdried bamboo which were the more than $18000 \mathrm{MPa}$ as studed by Razak et al., [8].

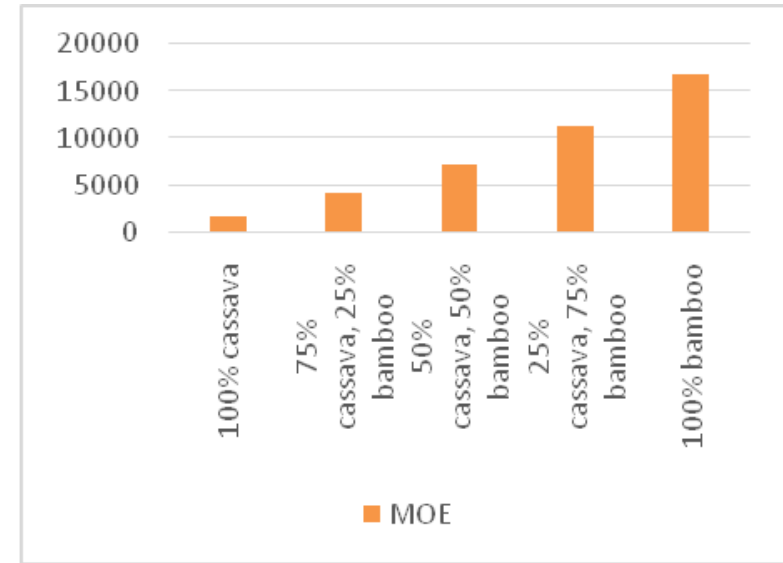

Fig 4 The MOE $\left(\mathrm{N} / \mathrm{mm}^{2}\right)$ of cassava-bamboo composite lumber

It is similar to the MOR result which can be observed from Figure 5 where the highest MOR was in the $100 \%$ bamboo which is $122.52 \mathrm{~N} / \mathrm{mm}^{2}$. The MOR strength increase with the increasing bamboo content which is similar to the value of MOE.

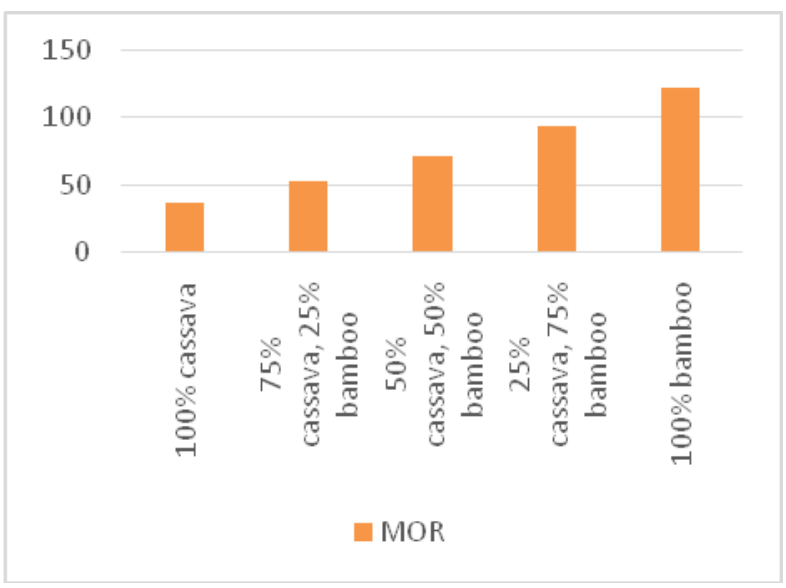

Fig 5 The MOR $\left(\mathrm{N} / \mathrm{mm}^{2}\right)$ of cassava-bamboo composite lumber

The result for parallel compression test as in Figure 6. Similar to MOE and MOR, the value for compression test increase with increasing bamboo content in the composite lumber. For composite lumber with $100 \%$ cassava, the compression value is only $32.86 \mathrm{~N} / \mathrm{mm}^{2}$ compared to $100 \%$ bamboo with 65.58 $\mathrm{N} / \mathrm{mm}^{2}$. The value of compression parallel to the grain of bamboo in this study was comparable with the value of air-dried Bambusa vulgaris as determined by Razak et al., [8]. 


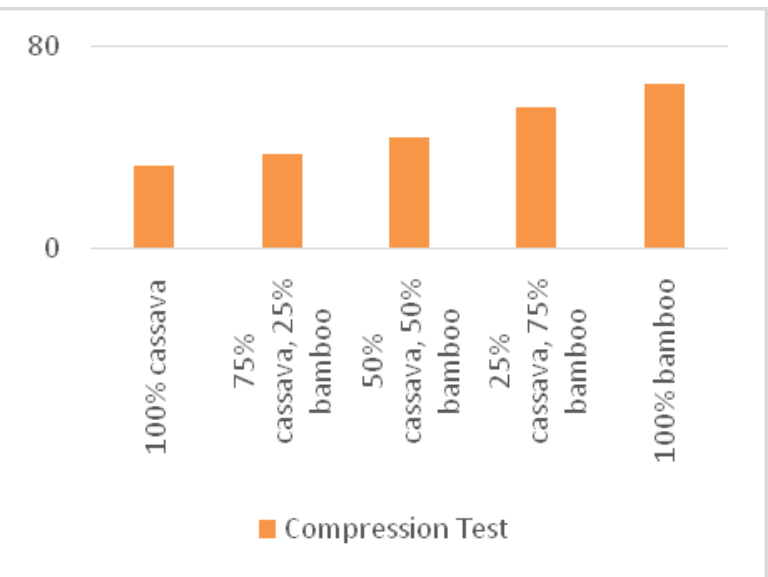

Fig 6 The compression test value $\left(\mathrm{N} / \mathrm{mm}^{2}\right)$ of cassavabamboo composite lumber

Table 1 shows the correlation between CBCL with all the properties tested. All the properties of CBCL were significantly related to each other. That is why the result indicates that the density, MOE, MOR and compression increases with increase use to bamboo in the composite lumber.

Table 1 Correlation between the properties of CBCL

\begin{tabular}{|c|c|c|c|c|}
\hline & $\begin{array}{c}\text { Basic } \\
\text { density }\end{array}$ & MOE & MOR & Compression \\
\hline Basic density & 1 & $0.9683^{*}$ & $0.9642^{*}$ & $0.9538^{*}$ \\
\hline MOE & & $0.9928^{*}$ & $0.9974^{*}$ & $0.9833^{*}$ \\
\hline MOR & & & $0.9912^{*}$ & $0.9820^{*}$ \\
\hline Compression & & & & 1 \\
\hline
\end{tabular}

*significant at $\mathrm{p} \leq 0.01$

\section{CONCLUSION}

The physical tests that have been carried out concluded that different ratio of cassava and bamboo affected the physical characteristics of the composite lumber. The value of the base density of the composite board studied increases when more bamboo mixed in the composite board. It was found that the use of bamboo and cassava wood is suitable to be used as composite lumber. This was evident by the value shown in the mechanical tests. In static bending tests and compression test, results show relatively high values at $100 \%$ bamboo ratio compared to other strip ratios. Based on the studies conducted, it can be seen that the CBCL is capable of replacing other timber products using logs or sawn timber. This can be seen based on the results of the mechanical tests as well as the physical tests obtained. The composite wood can be used as a board for the floor, as a base material for wood furniture and so on.

\section{ACKNOWLEDGMENTS}

The authors acknowledged the financial support provided by the University College of Technology Sarawak and also the Universiti Malaysia Sabah for allowing us to conducts the studies there.

\section{REFERENCES}

[1] Ferraro, V., Piccirillo, C., Tomlins, K., \& Pintado, M. E. (2016). Cassava (Manihot esculentaCrantz) and Yam (Dioscorea spp.) crops and their derived foodstuffs: safety, security and nutritional value. Critical reviews in food science and nutrition, 56(16), 2714-2727.

[2] Howeler, R. (2006, May). Cassava in Asia: trends in cassava production, processing and marketing. In Workshop on "Partnership in modern science to develop a strong cassava commercial sector in Africa and appropriate varieties by (Vol. 2020, pp. 2-6).

[3] Nhassico, D., Muquingue, H., Cliff, J., Cumbana, A., \& Bradbury, J. H. (2008). Rising African cassava production, diseases due to high cyanide intake and control measures. Journal of the Science of Food and Agriculture, 88(12), 2043-2049.

[4] Koshy, K. C., \& Pushpangadan, P. (1997). Bambusa vulgaris blooms, a leap towards extinction? Current Science, 72(9), 622-624.

[5] Ramesh, M. (2016). Kenaf (Hibiscus cannabinus L.) fibre based bio-materials: A review on processing and properties. Progress in Materials Science, 78, 1-92.

[6] Ong, H. C., Mahlia, T. M. I., Masjuki, H. H., \&Norhasyima, R. S. (2011). Comparison of palm oil, Jatropha curcas and Calophylluminophyllum for biodiesel: a review. Renewable and Sustainable Energy Reviews, 15(8), 3501-3515.

[7] Anokye, R., Bakar, E. S., Abare, A. Y., Kalong, R. M., \& Muhammad, A. (2014). The difference in density along the bamboo culms of Gigantochloa scortichinii and Bambusa vulgaris. International Journal of Emerging Technology and Advanced Engineering, 4(10), 638-643.

[8] Wahab, R., Samsi, H. W., Sulaiman, O., Salim, R., \& Hashim, R. (2007). Properties of oil-cured cultivated Bambusa vulgaris. International Journal of Agricultural Research, 2(9), 820-825 